\title{
Joint perturbation of geoacoustic, emanation, and atmospheric electric fields at the boundary of the earth's crust and the atmo- sphere before an earthquake
}

\author{
Oleg Rulenko ${ }^{1,2, \star}$, Yuriy Marapulets ${ }^{2, \star \star}$, Yuriy Kuzmin ${ }^{3, \star \star \star}$, and Alexandra Solodchuk ${ }^{2, \star \star \star \star}$ \\ ${ }^{1}$ Institute of Volcanology and Seismology, Far Eastern Branch, Russian Academy of Sciences, Russia, \\ 683006, Petropavlovsk-Kamchatskiy, boulevard Piypa, 9 \\ ${ }^{2}$ Institute of Cosmophysical Research ans Radio Wave Propagation, Far Eastern Branch, Russian Academy \\ of Sciences, Russia, 684034, Kamchatska region, Elizovskiy district, Paratunka, Mirnaya str., 7 \\ ${ }^{3}$ Kamchatka Branch, Geophysical Service, Russian Academy of Sciences, Russia, 683006, Petropavlovsk- \\ Kamchatskiy, boulevard Piypa, 9
}

\begin{abstract}
The possibility of joint perturbation of geoacoustic, emanation and atmospheric electric fields by the Earth's crust - atmosphere boundary before an earthquake is considered. In order to detect it, simultaneous registration of these fields was carried out in Kamchatka in August-October 2012. Synchronous anomalous disturbances were recorded 13 days before an earthquake with the magnitude $M_{w}=5.6$ at the distance of $140 \mathrm{~km}$ from an epicenter. It may be considered to be a complex short-term precursor.
\end{abstract}

\section{Introduction}

The boundary between the lithosphere and the atmosphere is characterized by significant changes of properties of the contacting mediums, considerable flows of mass and energy, a wide list of simultaneously existing dissimilar fields and their interactions and transformations [1]. A constituent part of interaction of the solid and the gas geospheres is the lithosphere effect on the atmosphere. It manifests partially in anomalous changes of geophysical fields in the near ground atmosphere in the result of geodynamic processes in the Earth's crust and is intensive in seismically active regions at the final stage of earthquake preparation.

Among different near-surface fields, the joint behavior of geoacoustic, emanation, and atmospheric electric fields before earthquakes deserves our attention. By the present time, many researchers have determined pre-seismic perturbations of these different fields, but they have not been registered simultaneously. Joint analysis of the perturbations of different fields improves the reliability of detection of earthquake precursors and may be the basis for investigation of the process of their preparation [2], [3].

\footnotetext{
^e-mail: rulenko@kscnet.ru

$\star \star$ e-mail: marpl@ikir.ru

$\star \star \star$ e-mail: kuzy@emsd.ru

$\star \star \star \star$ e-mail: aleksandra@ikir.ru
} 
It is generally accepted that mechanic processes play the main role in the preparation of a tectonic earthquake. They cause changes of the Earth's crust stress state which in the result of its inhomogeneous hierarchical block structure determine complicated spatial-temporal deformations of rocks, in particular their local tensions and compressions. Fig. 1 shows a scheme of generation of joint perturbation of geoacoustic, emanation and atmospheric field by the boundary of the Earth's crust and the atmosphere before an earthquake in the presence of sedimentary rocks and their tension at the observation site. The scheme was made by the authors on the basis of colligation and analysis of the results of theoretical investigations and natural observations from the world literature. Pre-seismic perturbations of these fields just like precursors in other fields, cause changes of the stress field in the zone of earthquake preparation. They occur in the result of transformations of stress-deformation tensions of the near-surface sedimentary rocks at an observation point. They have their peculiarities of genesis but common deformation nature.

Tension of sedimentary rocks having polydisperse fluid-saturated porous low-tensile structure is accompanied by relative displacement of fragments, their rehandling and, as a consequence, generation of acoustic signals. Simultaneously with that, in the result of opening of contacting surfaces, increase of rock emanation, opening of isolated pores and crack widening, radon and thoron concentrations in the soil gas increase as well as their penetration into the atmosphere that increases near-surface air ionization. In case of fair weather conditions, this process is accompanied by generation of negative electric charge in the near-surface layer of the thickness from tens of meter fractions to several meters [4], [5]. Its density may reach high values. Near such a charge and lower, the normal atmospheric electric field decreases and even changes its sign ([6] - short review). Generation and dissipation of the negative volume charge causes electric field bay decrease which is observed before earthquakes [7]-[9]. The general factor promoting the considered processes is the fragmentariness of sedimentary rocks and, as a consequence, their high deformability.

\section{Observations and results}

In August-October 2012, volumetric activity of radon $R n$ and thoron $T n$ in the surface layer, geoacoustic emission in the frequency range of $0.7-2.0 \mathrm{kHz}$, atmospheric electric field potential gradient at the altitude of $7 \mathrm{~cm}$ from the ground surface, air pressure, wind velocity and rain intensity were simultaneously measured for the first time at "Karymshina" site $\left(52.83^{\circ} \mathrm{N}, 158.13^{\circ} \mathrm{E}\right)$ of the Institute of Cosmophysical Research and Radio Wave Propagation FEB RAS [6]. Stored energy of earthquakes occurred at the distance of $R \leq 250 \mathrm{~km}$ from this site was considered to be the characteristic of the local seismic activity. Data of the regional catalogue of Kamchatka Branch of Geophysical Service RAS were applied (http://emsd.ru).

Fig. 2 illustrates a graph of energy storage of the considered earthquakes, air pressure variations and emanation volumetric activity. It is clear from Fig. 2, that high increases of $R n$ and $T n$ were only on October 2. They lasted for about 8 hours. Increase of emanation volumetric activity, electric field decrease and geoacoutsic emission increase at three measurement points forming a triangle with the sides of 10-35 m occurred during fair weather conditions (absence of rain, strong or moderate wind, air pressure was weakly changing, Fig. 3). During the period of measurements of 52 days, geoacoustic emission increases and close to it in time the electric field decreases with sing change were not observed any more. That indicates non-meteorological nature of these perturbations.

Joint anomalous perturbation of the fields was observed 13 days before the earthquake with $K_{s}=13.5$ which occurred on October 152012 at 01:19 UTC at the distance of $140 \mathrm{~km}$ from "Karymshina" site. Epicenter coordinates are $51.900^{\circ} \mathrm{N}, 159.379^{\circ} \mathrm{E}$, the depth of a source is $21 \mathrm{~km}$, moment magnitude $M_{w}=5.6$ (NEIC catalogue, http://earthquake.usgs.gov). This earthquake was accompanied by aftershocks. The strongest occurred on October 15 at $22: 45$. It had $K_{s}=12.6$, the 


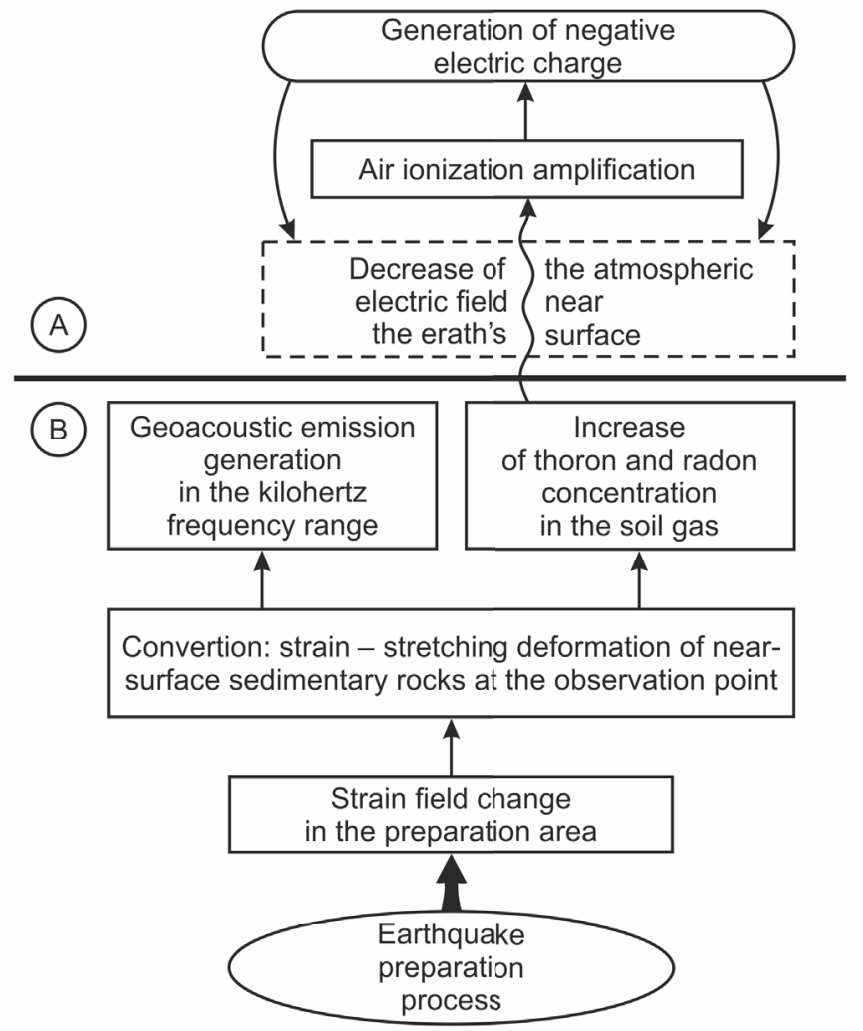

Figure 1. Scheme of generation of the joint perturbation of geoacoustic, emanation and atmospheric electric fields by the boundary of the Earth's crust and atmosphere before an earthquake. A — ground air, B - nearsurface sedimentary rocks.

epicenter coordinates are $51.810^{\circ} \mathrm{N}, 159.519^{\circ} \mathrm{E}$, the depth of a source is $35 \mathrm{~km}$. It is clearly seen on the graph of seismic energy storage (Fig. 2).

A well No. 99-8 of Kamchatka Branch of Geophysical Service RAS is located $120 \mathrm{~m}$ from the measurement field. Its depth is $19 \mathrm{~m}$. Its lithologic log is presented by the following rocks: washpebbly deposits with sandy-argillaceous filling $(0-5 \mathrm{~m})$, wash-rubbly deposits with argillaceous filling (5-14 m), wash-pebbly deposits with sandy filling $(14-19 \mathrm{~m})$. Water statistic level is $13.7 \mathrm{~m}$. Thus, near-surface rocks in "Karymshina" site are sedimentary. The thickness of the layer is $50 \mathrm{~m}$.

The theoretical radius of precursor manifestations in the Earth's surface deformations, known as $r=e^{M}(\mathrm{~km})$, is $270 \mathrm{~km}$ for the main earthquake on October 15 . It is significantly larger than the epicentral distance of "Karymshina" site which is located in the zone of intersection of tectonic faults of different ranks. Fault zones are characterized by increased tectonic sensitivity of different fields and by their stronger variations [10], as well as by stronger perturbations of fields before earthquakes [3]. Thus, the seismogenic nature of anomalous perturbations on October 2 is quite real.

Anomalous increase of radon and thoron with the duration of about $8 \mathrm{~h} 13$ days before the earthquake on October 15 with $M_{w}=5.6, R=140 \mathrm{~km}$ agrees well with the results of the paper [11]. In that 


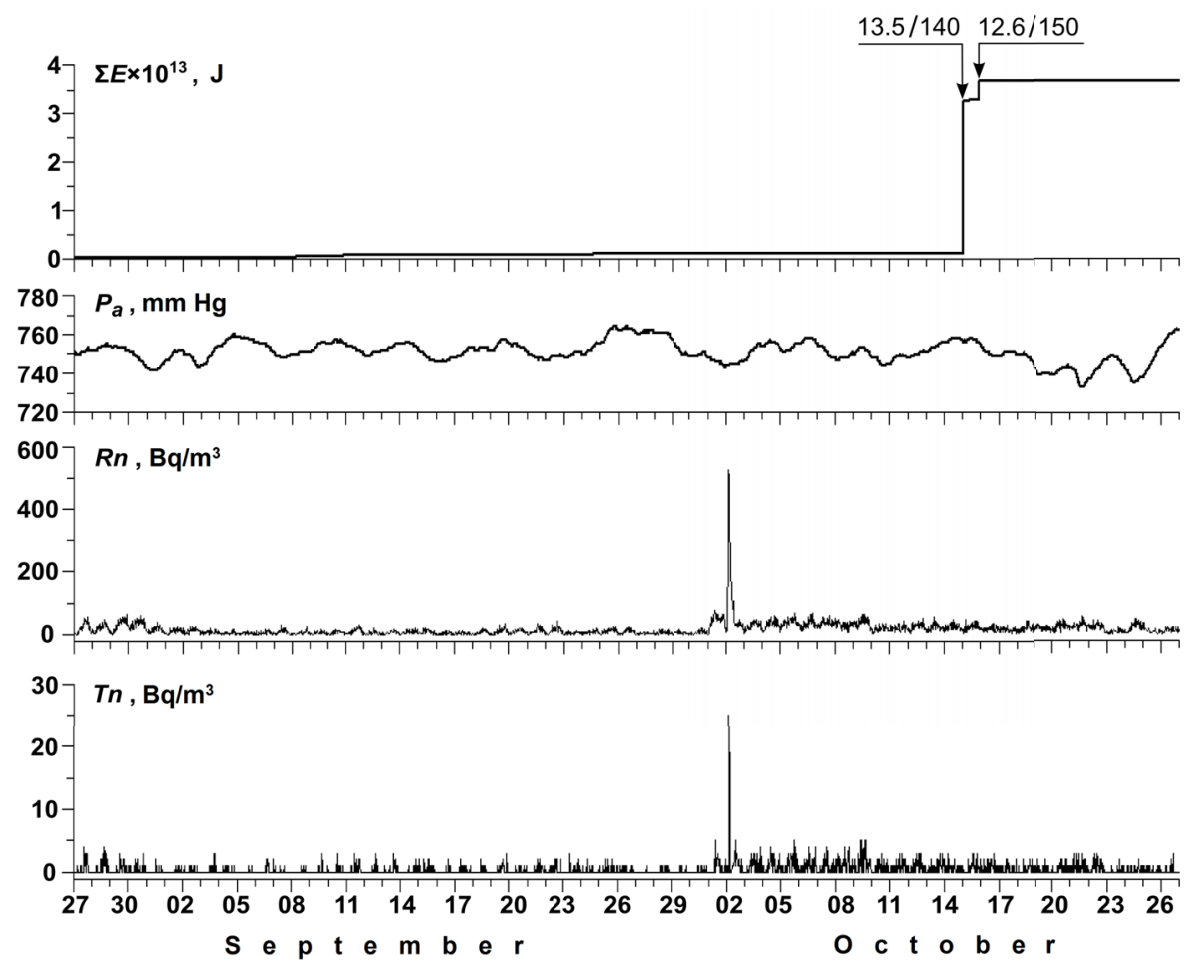

Figure 2. Graph of energy storage $\sum E$ of earthquakes with $K_{s}>9.0$ which occurred in the region of sampling, air pressure variations $P_{a}$, volumetric activity of radon $R n$ and thoron $T n$ during the observations. The left arrow indicates the time of the main earthquake on October 15 2012, the right arrow indicates the strongest aftershock. The first number over the error is $K_{s}$, the second number is the epicentral distance, $\mathrm{km}$.

paper, simultaneous increases of radon and toron in the soil gas before an earthquake with $M_{L} \geq 4.5$, $R<150 \mathrm{~km}$ was registered in the zone of an active fault in Taiwan. They usually occurred 1-20 days before an event and had the least duration of 5-7 h.

Radon and thoron differ insignificantly in physical and chemical properties except for the halflife which is 3.825 days and $55.6 \mathrm{~s}$, respectively. Due to the short period of half-life, thoron cannot migrate far from the place of formation, its mass transfer is of surface character. When entering into the atmosphere, it comes out of the soil layer with the thickness of $6 \mathrm{~cm}$. Its first $2 \mathrm{~cm}$ give up to $75 \%$ of emanation [12]. The large period of half-life allows the radon to come out from the depths of 10$12 \mathrm{~m}$ by diffusive mass transfer during the time equal to three-four periods [13]. During sedimentary rock tension, this depth becomes larger.

The anomalous disturbance of geoacoustic, emanation and atmospheric electric fields registered on October 2 may be considered to be a complex short-term precursor of the earthquake which occurred on October 15 with $M_{w}=5.6$ and as the indication of the Earth's crust effect on the surface atmosphere during its preparation. The affecting physical agents were radon and thoron. Stronger outflows of these emanations from the ground increases surface air ionization. It is accompanied by generation of negative volume charge in fair weather conditions well known in the atmospheric electricity. It decreases the electric field. 


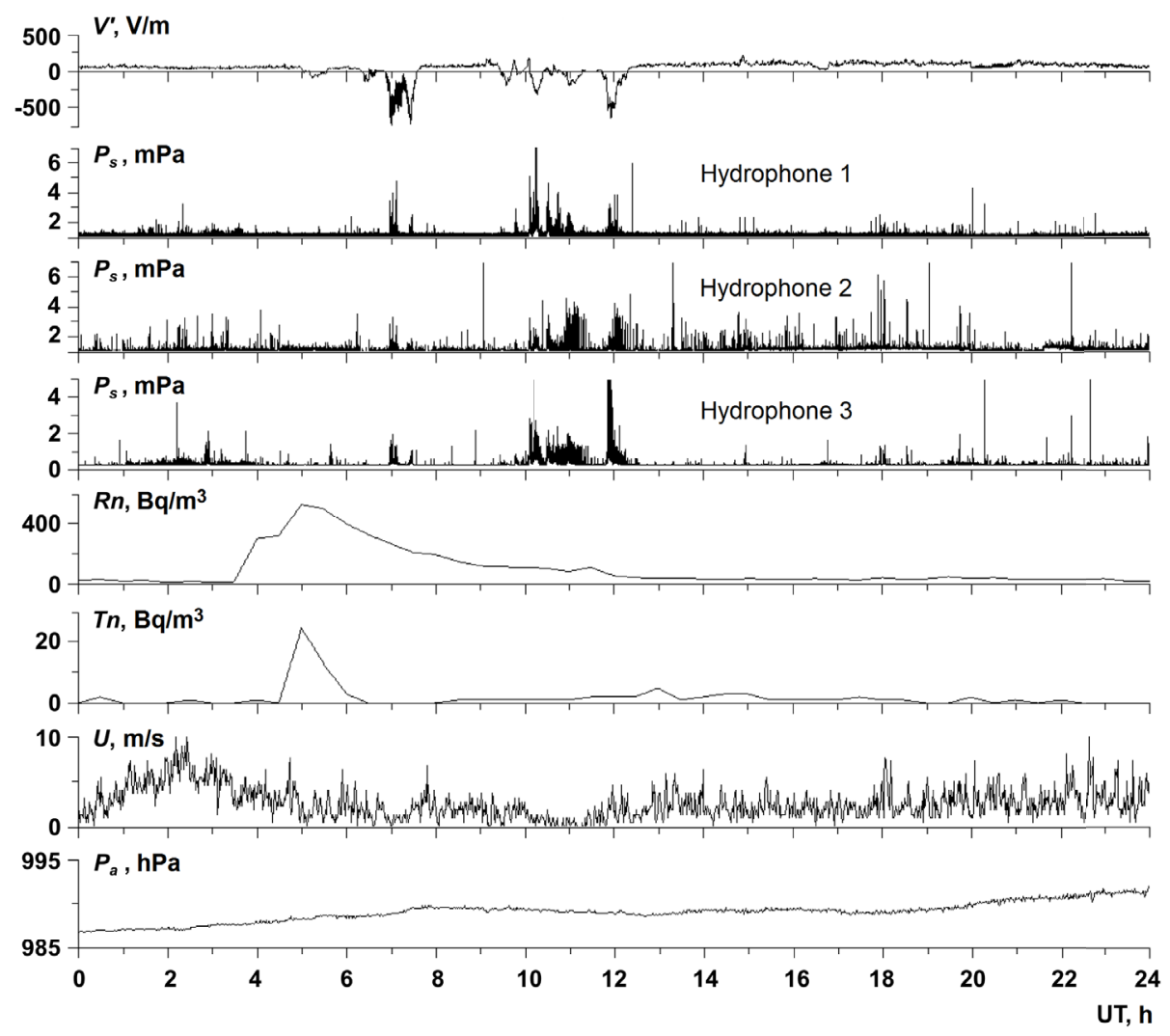

Figure 3. Variations of potential gradient $V^{\prime}$ of the atmospheric electric field, of acoustic pressure $P_{s}$ at three measurement points, of volumetric activity of emanations, wind velocity $U$ at the height of $8 \mathrm{~m}$ from the ground and atmospheric pressure $P_{a}$ on October 2, 2012.

\section{Conclusions}

We have suggested a scheme of joint perturbation of geoacoustic, emanation and atmospheric electric fields by the boundary of the Earth's crust and atmosphere before the earthquake in the presence of sedimentary rocks and their tension at the observation site. Simultaneous registration of these fields has been carried out for the first time. Their joint anomalous disturbance has been discovered. It was observed 13 days before the earthquake with the magnitude of $M_{w}=5.6$ at the distance of $140 \mathrm{~km}$ from the epicenter. The discovered perturbation may be considered as a complex short-term precursor of the earthquake and the indication of the Earth's crust effect on the surface atmosphere during its preparation.

\section{References}

[1] Adushkin V. V., Spivak A. A., Izvestiya. Physics of the Solid Earth 48:3, 181-198 (2012)

[2] Sobolev G. A., Ponomarev A. V., Fizika zemletryaseniy i predvestniki [Earthquakes physics and precursors] (Nauka, Moskva, 2003) 270 p. 
[3] Kissin I. G., Flyuidy v zemnoy kore: Geofizicheskie i tektonicheskie aspekty [Fluids in the earth's crust: Geophysical and tectonic aspects.] (Nauka, Moskva, 2015) 328 p.

[4] Hoppel W. A., J. Atmos. Terr. Phys. 29 (6), 709-721 (1967)

[5] Kulkarni M., Kamra A. K., J. Geophys. Res. 106 (D22), 28209-28221 (2001)

[6] Rulenko O. P. Marapulets Yu. V., Kuzmin Yu. D., Doklady Earth Sciences 461:1, 307-311 (2015)

[7] Rulenko O. P., Volcanology and Seismology 22:4, 435-451 (2001)

[8] Choudhury A., Guha A., Kumar De B., Roy R., Annals of Geophysics 56 (3), 331-340 (2013)

[9] Kachakhidze N., Kachakhidze M., Kereselidze Z., Ramishvili G., Nat. Hazards Earth Syst. Sci. 9, 1221-1226 (2009)

[10] Spivak A. A., Izvestiya. Physics of the Solid Earth 46:4, 327-338 (2010)

[11] Yang T. F., Walia V., Chyi L. L. et al, Radiation Measurements 40, 496-502 (2005)

[12] Guedalia D., Laurent J - L., Fontan J. et al, J. Geophys. Res. 75 (2), 357-369 (1970)

[13] Abduvaliev A.K. et al., Doklady Akademii Nauk SSSR 271:1, 72-75 (1983) 